\title{
The predictive value of psychological assessment of candidates for gastric bypass: A medical chart review
}

\author{
Nathalie Aubert ${ }^{\star}$ \\ Isabelle Lyon-Pagès* \\ Isabelle Carrard* \\ Michel Suter** \\ Friedrich Stiefel ${ }^{\star}$ \\ Vittorio Giusti***
}

* Service de Psychiatrie de Liaison, Centre Hospitalier Universitaire Vaudois (CHUV), Lausanne

** Service de Chirurgie Viscérale, Centre Hospitalier Universitaire Vaudois (CHUV), Lausanne

*** Consultation d'Obésité et troubles du comportement alimentaire, Centre Hospitalier Universitaire Vaudois (CHUV), Lausanne

\section{SWITZERLAND}

ABSTRACT - Background and Objectives: Guidelines for bariatric surgery demand a psychological evaluation of applicants. The aim of this study was to evaluate if the presence of "psychological risk factors" predicts postoperative weight loss after gastric bypass.

Methods: Medical records of obese women who underwent bariatric surgery between 2000 and 2004 were reviewed. Psychological assessment consisted of a one-hour semistructured interview, summarized in a written report. Anthropometric assessment at baseline and 6,12,18 and 24 months after surgery included body weight, height and body mass index.

Results: The mean BMI of included patients $\left(\mathrm{N}=92\right.$ ) was $46.2+6,3 \mathrm{~kg} / \mathrm{m}^{2}$ (range 38.4 $-69.7)$. Based on the psychological assessment, $27 \%(\mathrm{~N}=25)$ of the patients were classified as having "psychological risk factors" and $28 \%(\mathrm{~N}=26)$ were diagnosed with a psychiatric diagnosis, most often major depression. Two years after gastric bypass, $16 \%$ of patients with "psychological risk factors" achieved an excellent result (\%EWL > 75) versus $39 \%$ of those without $(\mathrm{p}<0.05)$. About 1 out of 4 patients was in postoperative psychiatric treatment, but only half of them were identified as having "psychological risk factors" at baseline. Weight loss of patients initiating a psychiatric treatment only after 
surgery was less than of patients who continued psychiatric treatment already initiated before surgery $(55.7+14.8$ versus $66.5+14.2 \% \mathrm{EWL})$.

Conclusions: A single semi-structured psychological interview may identify patients who are at risk for diminished postoperative weight loss; however, psychological assessment did not identify those patients who were in need of a psychiatric postoperative treatment.

Received: 21 October 2009

Revised: 1 February 2010

Accepted: 8 February 2010

\section{Introduction}

The prevalence of obesity has markedly increased in the Western world during the past 20 years, leading to a growing prevalence of obesity-related comorbidities ${ }^{1-4}$, which interfere with quality of life $\mathrm{e}^{5,6}$. This context and the development of less invasive laparoscopic surgery have led to a significant increase in the number of bariatric surgical procedures performed each year ${ }^{7-9}$. Bariatric surgery has been shown to produce effective and sustainable weight loss, improvement of obesity-related comorbidities, quality of life and survival ${ }^{10-13}$.

Gastric banding and Roux-en-Y-gastric bypass, the now most commonly performed surgical procedures ${ }^{14,15}$, lead to rapid and drastic changes in eating behavior and weight and body perceptions, which may cause psychological disturbances ${ }^{16-19}$. Moreover, up to half of the candidates for bariatric surgery already present psychological disturbances, such as depression, anxiety and/or personality disorders ${ }^{20-24}$. Furthermore, about two thirds of obese patients report a history of child abuse and/or neglect, one out of four indicate having had psychiatric treatment in the past and between $12 \%$ and $38 \%$ use of psychotropic medication ${ }^{22,25-27 .}$

Therefore, the evaluation, selection, education and follow up of patients who under- go such surgery require a multidisciplinary approach by a team of endocrinologists, dieticians, psychiatrists and surgeons. The aim of the multidisciplinary management is to decrease the patients' preoperative risks (metabolic and nutritional complications) and to improve their adjustment to postoperative changes in eating behavior and body perceptions and thus to reduce the risk of psychological disturbances ${ }^{28-31}$.

Accordingly, the Bariatric Scientific Collaborative Group and the International Federation for the Surgery of Obesity demand a psychological evaluation of candidates for bariatric interventions ${ }^{32-34}$ in order to identify patients with a contraindication for surgery and to decrease psychological disturbances after surgery ${ }^{35-37}$.

Over the last years, a great number of studies reported on the psychological evaluation of patients for bariatric surgery. While these studies revealed an important prevalence of psychiatric disturbances among candidates, they did not focus on "patients psychological risk factors" for diminished treatment response $\mathrm{e}^{38}$.

The aim of this study was to evaluate if a psychological assessment in a "real world setting" identifies patients at risk for diminished outcome after bariatric surgery. More specifically, the hypothesis of this chart review was 
that the presence of "psychological risk factors" for diminished treatment response, identified by means of a semi-structured interview by a psychologist, predicts postoperative weight loss after gastric bypass.

If the hypothesis is confirmed, the design and implementation of psychological interventions targeted at this subgroup of patients should be considered.

\section{Patients and methods}

\section{Analysis of medical records and patient selection}

This study is a retrospective analysis of medical records of obese patients who were evaluated by a multidisciplinary team, including a psychologist, and who underwent bariatric surgery by Roux-en-Y-gastric bypass (RYGBP) at the University Hospital of Lausanne (CHUV).

Patients were considered for surgery if their body mass index (BMI) exceeded 40 $\mathrm{kg} / \mathrm{m}^{2}$, or $35 \mathrm{~kg} / \mathrm{m}^{2}$ with at least one comorbidity, and if other, non-operative treatments failed for at least 2 years.

All patients who underwent bariatric surgery between 2000 and 2004 were included in the chart review; medical records provided various information, such as sociodemographic data, history of obesity and weight loss attempts, eating patterns, physical activities, knowledge of and motivation for bariatric surgery, main biographical elements, major life events, and past and current psychiatric disturbances.

In order to constitute a homogeneous group, -an overwhelming majority of patients were females-, men were excluded from the analysis. We also excluded patients who: 1 ) were having gastric banding; 2) were secon- darily converted to RYGBP after having previously undergone an other bariatric procedure; 3 ) were lost for follow-up or attended less than four of the medical visits during the two years after RYGBP; 4) became pregnant during the two years after RYGBP; and 5) had an absolute contraindication for surgery (e.g. acute psychotic disorders and/ or uncontrolled substance abuse).

\section{Psychological assessment}

The assessment effectuated by the same psychologist -based on a one-hour semistructured interview, summarized in a written report- focused on patient's resources and vulnerabilities, cognitive, affective and socio-relational aspects, presence of a psychiatric diagnosis (ICD-10 criteria) and attitudes towards obesity and expectations with regard to surgery. Psychiatric disorders were diagnosed clinically, the "psychological risk factors" were categorized in (i) psychological disturbances, such as mental retardation, impulsive behavior, unstable psychiatric disorders (e.g.: active substance abuse) or uncontrolled eating disorder, a psychiatric diagnosis per se was not sufficient to be classified in this first category; (ii) socio-relational difficulties, such as traumatic life events, stressful psychosocial situations (e.g.-: repeated conflicts) or impaired social integration; and (iii) problematic attitudes towards surgery, such as ambivalence, unrealistic expectations or difficulties with compliance (e.g.: frequent missing of appointments).

As mentioned above, the study aimed to evaluate the predictive value of the psychological assessment in a "real world setting". The "psychological risk factors" were based on the psychologist's clinical experience with this patient population; the different categories have not been operationalized in detail, since they were not elaborated for re- 
search, but only for clinical purposes (structuring of the interview). The presence of a psychiatric diagnosis itself was not sufficient to be categorized as presenting a "psychological risk factor", except if the disorder was considered as unstable (risk of decompensation) or as negatively influencing comprehension of the treatment (e.g. mental retardation) or compliance (e.g. uncontrolled eating disorder).

\section{Anthropometric measurements}

The anthropometric assessment at baseline and 6, 12, 18 and 24 months after surgery included body weight and height, measured with a Detecto scale and stadiometer and the body mass index (BMI), calculated as weight $(\mathrm{kg})$ divided by the square of height $\left(\mathrm{m}^{2}\right)$. Weight loss was assessed using the initial percentage of excess weight loss (EWL) and the BMI. According to the criteria developed by Reinhold ${ }^{39}$, EWL was considered as excellent if more than $75 \%$, good if between $50 \%$ and $75 \%$ and fair if between $25 \%$ and $50 \%$ of excessive weight was lost.

\section{Statistical analysis}

All analyses were performed using the Jump 7 statistical package (the SAS Institute, Carry, NC) running on a PC. Means and standard deviation (SD) were calculated for age and anthropometric measurements. Comparison of patient data with and without the presence of "psychological risk factors" was assessed by analysis of variance and paired Student's t-test for all variables. Spearman's correlation was used to assess relationships between anthropometric and psychological parameters. Differences were interpreted as statistically significant at $\mathrm{p}<0.05$.

\section{Results}

\section{Sample}

Of the initial sample of 134 consecutive women who were evaluated for surgery, 42 were excluded (3 renounced to be operated, 5 were operated in other hospitals, 7 had medical contraindications, 26 lacked complete follow up and 1 was pregnant). In total 92 patients were included in the study.

\section{Sociodemographics and weight history}

Mean (+ SD) age of the study sample was $40+10$ years (range 19-60); 94\% ( $\mathrm{N}=86)$ were Caucasian; 59\% ( $\mathrm{N}=54)$ married, $25 \%(\mathrm{~N}=23)$ single and $16 \%(\mathrm{~N}=15)$ divorced or separated and $60 \%(\mathrm{~N}=55)$ were employed; $18 \%(\mathrm{~N}=78)$ had undertaken more than 5 intentional weight loss attemps and $64 \%(\mathrm{~N}=59)$ indicated a weight cycling syndrome, defined as at least 3 intentional weight reductions of more than $5 \mathrm{~kg}$ with a subsequent regain of more than $50 \%$ of the weight loss. No correlations were found between socio-demographic variables, weight history and post-operative weight loss.

\section{Psychological variables}

Based on the psychological evaluation, $42 \%(\mathrm{~N}=39)$ reported a past psychiatric disorder, 33\% $(\mathrm{N}=31)$ past psychiatric treatment and $38 \%(\mathrm{~N}=35)$ past psychotropic treatment; $28 \%(\mathrm{~N}=26)$ were diagnosed with a current psychiatric diagnosis, most often major depression $(\mathrm{N}=18)$.

About one third of the patients $(\mathrm{N}=25$, $27 \%$ ) were identified as having "psychological risk factors", mainly psychological disturbances $(\mathrm{N}=16)$ (criterion $\mathrm{i})$, followed by 
problematic attitudes towards treatment ( $\mathrm{N}$ =11) (criterion ii) and socio-relational difficulties $(\mathrm{N}=8)$ (criterion iii); multiple categories of "psychological risk factors" were present in ten patients.

Upon follow up, $26 \%$ of the patients $(\mathrm{N}=$ 24) indicated being treated by a mental health professional, and half of them $(\mathrm{N}=$ 12) initiated psychiatric treatment before bariatric surgery motivated by the identification of a "psychological risk factor" by the psychologist.

\section{Anthropometric parameters}

Mean weight was $122.9+19.2 \mathrm{~kg}$ (range 93-192) and mean BMI was $46.2+6.3 \mathrm{~kg} / \mathrm{m}^{2}$ (range 38.4-69.7). Patients with "psychological risk factors" were more obese with a preoperative BMI of $48.5 \mathrm{~kg} / \mathrm{m}^{2}$ versus 45.3 $\mathrm{kg} / \mathrm{m}^{2}(\mathrm{p}<0.05)$.

Comparison of patients in different categories of "psychological risk factors" to the rest of the sample revealed that the BMI was higher in patients classified in "problematic attitudes towards surgery" (BMI $52.1 \mathrm{~kg}$ / $\left.\mathrm{m}^{2}, \mathrm{p}<0.01\right)$ and "psychological disturbances" (BMI $49.3 \mathrm{~kg} / \mathrm{m}^{2}, \mathrm{p}<0.01$ ), whereas the difference was not significant for patients classified in "socio-relational" contraindication (BMI $44.7 \mathrm{~kg} / \mathrm{m}^{2}$ ).

\section{Weight loss and psychological risk factors}

At 6, 12, 18 and 24 month postoperative follow up, weight loss was significant for all patient with a mean \%EWL of $49+12.5$, $63.4+14.4,67.1+14.7$ and $66.8+14.4$ and mean BMI decreased from $46.2+6.6 \mathrm{~kg} / \mathrm{m}^{2}$ to $29.7+4.7 \mathrm{~kg} / \mathrm{m}^{2}$ ( $\left.\mathrm{p}<0.001\right)$ two years after surgery.
While at 24 months follow up there was a trend with regard to the difference in $\% \mathrm{EWL}$ between patient with $(62+12.7)$ and without "psychological risk factors" $(68.6+14.6)(\mathrm{p}$ $=0.055$ ), the curve evolution showed significant disparity: after 12 months, the curve of EWL of patients with "psychological risk factors" achieved a steady state (Figure 1A) and patients without still improved (Figure 1B). The most important difference in weight loss between the two groups was observed between 6 and 18 months postoperative $(\mathrm{p}<0.05)$.

The weight loss of patients initiating a psychiatric treatment after surgery was less than in patients who initiated psychiatric treatment before surgery: $55.7+14.8$ versus $66.5+14.2 \%$ EWL (not significant).

Significant differences were found between groups when the distribution of EWL during 24 months follow up was analyzed according to Reinhold's criteria (Figure 2): two years after gastric bypass $16 \%$ of patients with "psychological risk factors" achieved an excellent result (\% EWL > 75) versus $39 \%$ of those without $(\mathrm{p}<0.05) ; 18$ months after surgery, $16 \%$ of patients with a "psychological risk factor" achieved an excellent result (\% EWL > 75) versus $40 \%$ of those without $(\mathrm{p}<0.05)$. Additional analyses, based on other categories of Reinhold's criteria (for example 50-75\% EWL) did not reveal significant results between groups.

\section{Discussion}

Up to now, data are not available allowing to compare the predictive value of different types of psychological assessment to identify patients with a diminished treatment response. 

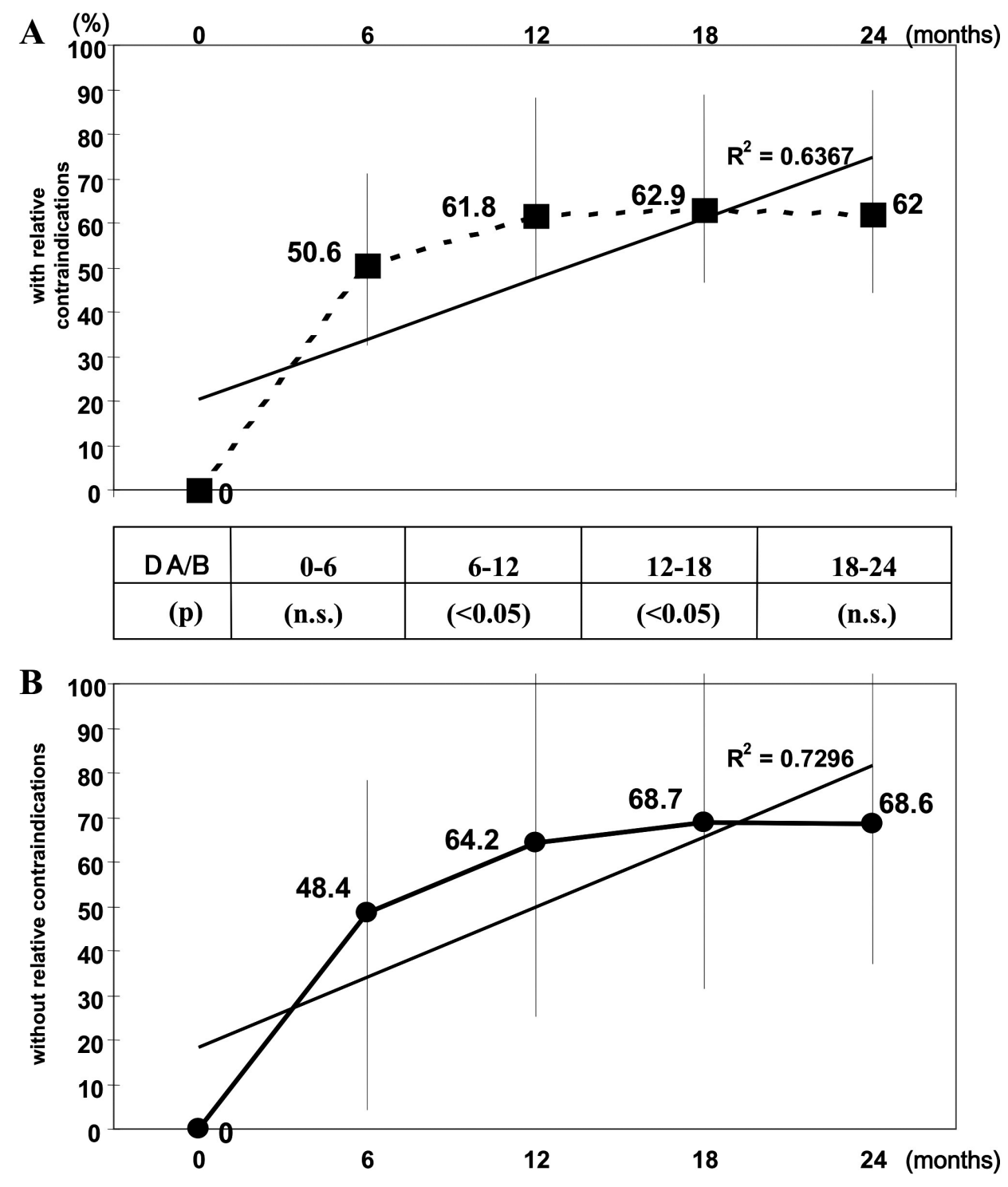

Figure 1. Comparison of excess weight loss (EWL) in patients with and without psychological contraindications. ( $\mathrm{p}=$ Student's t-test; $\Delta$ = variation in EWL every six moths between two group of patients). 


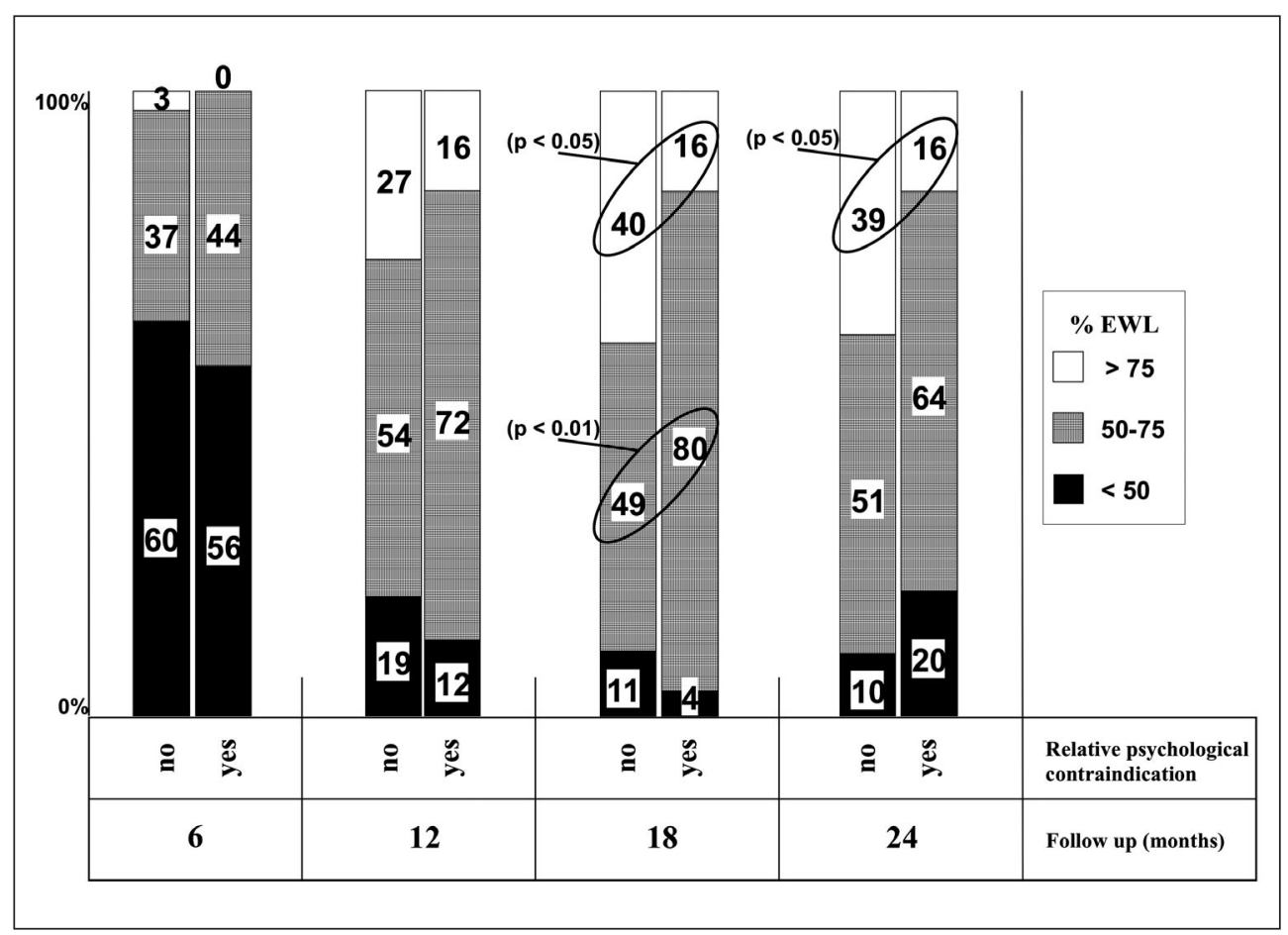

Figure 2. Distribution of excess weight loss (EWL) over time according to Reinhold's criteria in patients with and without contraindications $(\mathrm{p}=$ Student's t-test $)$.

Our results indicate that the presence of a "psychological risk factor" is a negative prognostic factor for postoperative weight loss, with less than 2 out of 10 patients achieving an excellent result in EWL according to Reinhold's criteria, while 4 out of 10 in patients without "psychological risk factors" reach excellent results. The negative impact of "psychological risk factors" on outcome is also supported by a trend in the divergence of the evolution of mean EWL curve between the two patient groups upon follow up.

The identification of "psychological risk factors" -originally searched to motivate patients to work on them and eventually to accept psychiatric treatment- has, however, a limited value: of the about 1 out of 4 patients who are in postoperative psychiatric treatment, only half of them were identified at baseline as presenting a "psychological risk factor" (and a psychiatric disorder) by the psychologist. This is especially important, since for patients who initiated psychological treatment before surgery, outcome is better; this may be due to the fact that adequate psychological support prior to surgery contributes to postoperative adjustment and thus improves also somatic outcome.

Despite the retrospective character, the limited outcome measures (Reinhold's criteria is only one of many ways to define success of postoperative weight loss), the short follow up (24 months), and the lack of operationalized and detailed categories of "psychological risk factors", the results of this study suggests new approaches of pa- 
tients who undergo bariatric surgery and design improvements for future prospective studies. More specifically, since the results of the psychological assessment are related to outcome, this assessment deserves to be structured and investigated. Future studies should adress this topic by comparing with a prospective design the predictive value of different types of psychological assessment. For example, the potential value to combine the use of psychiatric questionnaires with the single semi-structured interview ${ }^{40-43}$ should be evaluated. Evidence exists that the most frequent reasons for surgery delay motivated by psychologists are untreated or undertreated depression or anxiety disorders, lack of understanding of surgery, uncontrolled eating disorders, chaotic life circumstances and/or situational stressors, unrealistic expectations with regard to weight loss and expected life changes after surgery, poor social support or family conflicts ${ }^{44-46}$. A semi-structured interview, focused on these parameters and complemented by specific questionnaires assessing main psychiatric disturbances might and operationalized "psychological risk factors" therefore be a promising alternative to the single interview.

At present the three most widely used questionnaires in candidates for bariatric surgery are the Beck Depression Inventory, the Minnesota Multiphasic Personality Inventory-2 and the Millon Behavioral Medicine Diagnostic ${ }^{40}$. However, no data are yet available with regard to their efficacy to detect patients at risk for negative psychiatric or somatic outcome.

This study -very limited with regard to methodology number of patients lost during follow up and conclusions that can be drawnmay hopefully be a first step to initiate future prospective studies, evaluating the efficacy of different types of psychological assessment of candidates for bariatric surgery to identify patients at risk for suboptimal (somatic and psychiatric) outcome, who might benefit from targeted psychosocial interventions.

In conclusion, our model of preoperative psychological assessment, a single semistructured interview focusing on "psychological risk factors" for diminished treatment response seems to identify patients at risk for diminished weight loss, but lacks to identify all patients who could possibly benefit from psychological treatment and thus improve outcome.

\section{References}

1. Christakis N, Fowler J. The spread of obesity in a large social network over 32 years. N Engl J Med 2007; 357: 370-379.

2. Basham P, Luik J. Is the obesity epidemic exaggerated? Yes. BMJ 2008; 336: 244.

3. Jeffery R, Sherwood N. Is the obesity epidemic exaggerated? No. BMJ 2008; 336: 245.

4. Ogden CL, Yanovski SZ, Carroll MD, Flegal KM. The epidemiology of obesity. Gastroenterology 2007; 132: 2087-2102

5. World Health Organization. Obesity and overweight. Facts. www.who.int. 2004 [cited].

6. Residori L, García-Lorda P, Flancbaum L, Pi-Sunyer FX, Laferrère B. Prevalence of co-morbidities in obese patients before bariatric surgery: Effect of race. Obes Surg 2003; 13: 333-340.

7. Pories WJ, Bariatric Surgery: Risks and Rewards. J Clin Endocrinol Metab 2008; 93(11): S89-S96.

8. Treadwell JR, Sun F, Scholles K. Systematic review and meta-analysis of bariatric surgery for pediatric obesity. Ann Surg 2008; 248(5): 763-776.

9. Buchwald H, Avidor Y, Braunwald E, Jensen MD, Pories W, Fahrbach K, et al. Bariatric surgery : a systematic review and meta-amalysis. JAMA 2004; 292: 1724-1737.

10. Marsk R, Freedman J, Tynelius P, Rasmussen F, Näslund E. Antiobesity surgery in Sweden from 1980 to 2005. A population based study with a focus on mortality. Ann Surg 2008; 248(5): 777-781. 
11. Sjöström L, Lindroos AK, Peltonen M, Torgerson J, Bouchard C, Carlsson B, et al. Lifestyle, diabetes, and cardiovascular risk factors 10 years after bariatric surgery. N Engl J Med 2004; 351: 2683-2693.

12. Christou N, Sampalis JS, Liberman M, Look D, Auger S, McLean AP, et al. Surgery decreases long-term mortality, morbidity, and health care use in morbidly obese patients. Ann Surg 2004; 240: 416-424.

13. Suter M, Paroz A, Calmes JM, Giusti V. European experience with laparoscopic Roux-en-Y gastric bypass in 466 obeses patients. Brit J Surg 2006; 93: 726-732.

14. Saber AA, Elgamal MH, McLeod MK. Bariatric Surgery: The Past, Present, and Future. Obes Surg 2008; 18: 121-128.

15. Maggard MA, Shugarman LR, Suttorp M, Maglione M, Sugerman HJ, Livingston EH, et al. Meta-Analysis: Surgical Treatment of Obesity. Ann Intern. Med 2005; 142 : 547-559.

16. Van Hout GCM., Vreeswijk CMJM, van Heck GL. Bariatric Surgery and Bariatric Psychology : Evolution of the Dutch Approach. Obes Surg 2008; 18: 321-325.

17. Guisado JA, Vaz FJ, Alarcón J, López-Ibor JJ Jr, Rubio MA, Gaite L. Psychopathological Status and Interpersonal Functioning Following Weight Loss in Morbidly Obese patients Undergoing Bariatric Surgery. Obes Surg 2002; 12: 835-840.

18. Burgmer R, Grigutsch K, Zipfel S, Wolf AM, de Zwaan M, Husemann B, et al. The Influence of Eating Behavior and Eating Pathology on Weight Loss after Gastric Restriction Operations. Obes Surg 2005; 15: 684-691.

19. Rosik CH. Psychiatric Symptoms among Prospective Bariatric Surgery Patients: Rates of Prevalence and their Relation to Social Desirabiliry, Pursuit of Surgery, and Follow-Up Attendance. Obes Surg 2005; 15: 677-683.

20. Fabricatore AN, Wadden TA, Sarwer DB, Faith MS. Health.Related Quality of Llife and Symptoms of Depression in Extremely Obese Persons Seeking Bariatric Surgery. Obes Surg 2005; 15: 304-309.

21. Sarwer DB, Cohn NI, Gibbons LM, Magee L, Crerand CE, Raper SE, et al. Psychiatric Diagnoses and Psychiatric Treatment among Bariatric Surgery Candidates. Obes Surg 2004; 14: 1148-1156.

22. Sarwer D, Wadden TA, Fabricatore AN. Psychosocial and behavioral aspects of bariatric surgery. Obes Research 2005; 13: 639-648.

23. Walfish S. Psychological Correlates of Laparoscopic Adjustable Gastric Band and Gastric Bypass Patients. Obes Surg 2008 Aug 30 [Epub ahead of print].
24. Henrickson HC, Ashton KR, Windover AK, Heinberg LJ. Psychological Considerations for Bariatric Surgery among Older Adults. Obes Surg 2009; 19(2): 211-216.

25. Grilo C, Masheb RM, Brody M, Toth C, Burke-Martindale $\mathrm{CH}$, Rothschild BS. Chilhood maltreatment in extremely obese male and female bariatric surgery candidates. Obes Res 2005; 13: 123-130.

26. Wadden TA. Adverse psychosicial consequences of extreme obesity and the effects of surgically induced weight loss. Surg Obes Relat Dis 2005; 1: 56-58.

27. Wildes JE, Kalarchian MA, Marcus MD, Levine MD, Courcoulas AP. Chilhood Maltreatment and Psychiatric Morbidity in Bariatric Surgery Candidates. Obes Surg 2008; 18: 306-313.

28. Lanyon RI, Maxwell BM, Kraft AJ. Prediction of Long-term Outcome after Gastric Bypass Surgery. Obes Surg 2009; 19(4): 439-445.

29. Saltzman E, Anderson W, Apovian CM, Boulton H, Chamberlain A, Cullum-Dugan D, et al. Criteria for Patient Selection and Multidisciplilnary Evaluation and Treatment of the Weight Loss Surgery Patient. Obes Res 2005; 13(2): 234-243.

30. Dziurowicz-Kozlowska AH, Wierzbicki Z, Lisik W, Wasiak D, Kosieradzki M. The objective of psychological evaluation in the process of qualifying candidates for bariatric surgery. Obes Surg 2006; 16(2): 196-202.

31. Gorin AA, Raftopoulos I. Effect of Mood and Eating Disorders on the Short-Term Outcome of Laparoscopic Roux-en-Y Gastric Bypass. Obes Surg 2009; 19(12): 1685-1690.

32. Fried M, Hainer V, Basdevant A, Buchwald H, Deitel $\mathrm{M}$, Finer N, et al. Inter-disciplinary European guidelines on surgery of severe obesity. Int J Obes. 2007; 31: 569-577.

33. Melissas J. IFSO Guidelines for Safety, Quality, and Excellence in Bariatric Surgery. Obes Surg 2008; 18: 497500 .

34. Mechanick JI, Kushner RF, Sugerman HJ, Gonzalez-Campoy JM, Collazo-Clavell ML, Guven S, et al. AACE/TOS/ASMBS Guidelines for Clinical Practice for the Perioperative Nutritional, Metabolic, and Nonsurgical Support of the Bariatric Surgery Patient. Endocr Pract 2008; 14(Suppl 1): 1-83.

35. Bauchowitz A, Gonder-Frederick LA, Olbrisch MH, Azarbad L, Ryee MY, Woodson M, et al. Psychosocial Evaluation of Bariatric Surgery Candidates : A Survey of Present Practices. Psychosom Med 2005; 67: 825-832.

36. Greenberg I, Perna F, Kaplan M, Sullivan MA. Behavioral and Psychological Factors in the Assessment and 
treatment of Obesity Surgery Patients. Obes Res 2005; 13 : 244-249.

37. Norris L. Psychiatrics Issues in Bariatric Surgery. Psychiatr Clin N Am 2007; 30: 717-738.

38. van Hout GCM, Verschure SKM, van Heck GL, Psychosocial Predictors of Success following Bariatric Surgery. Obes Surg 2005; 15: 552-560.

39. Reinhold R, Critical analysis of long term weight loss following gastric bypass. Surg Gynecaol Obstet 1982; 155: 385-394.

40. Walfish S, Vance D, Fabricatore AN. Psychological Evaluation of Bariatric Surgery Applicants: Procedures and reasons for Delay or Denial of Surgery. Obes Surg 2007; 17: 1578-1583.

41. Hrabosky JI, White MA, Masheb R. Psychometric Evaluation of the Eating Disorder Examination-Questionnaire for Bariatric Surgery Candidates. Obesity 2008; 16(4): 763-769.

42. Callegari A, Michelini I, Sguazzin C, Catona A, Klersy C. Efficacy of the SF-36 Questionnaire in Identifying Obese Patients with Psychological Discomfort. Obes Surg 2005; 15: 254-260.
43. Kinder BN, Walfish S, Scott Young M, Fairweather A. MMPI-2 Profiles of Bariatric Surgery Patients : A Replication and Extension. Obes Surg 2008; 18(9): 1170-1179.

44. Abiles V, Rodriguez-Ruiz S, Abiles J, Mellado C, Garcia A, Perez Fernandez-Santaella MC. Psychological Characteristics of Morbidly Obese Candidates for Bariatric Surgery. Obes Surg 2010; 20(2): 161-167.

45. Sogg S, Mori DL. Psychosocial Evaluation for Bariatric Surgery : The Boston Interview and Opportunities for Intervention. Obes Surg 2009; 19(3): 369-377.

46. Sogg S, Mori DL. Revising the Boston Interview : Incorporating new knowledge and experience. Surg Obes Relat Dis 2008; 4: 455-463.

Address for correspondence:

Vittorio Giusti, MD

Service of Endocrinology, Diabetology and Metabolism University Hospital,CHUV, Bugnon 44,1011 Lausanne, Switzerland

Phone: 0041-21-3140642

Fax: 0041-21-3140628

E-mail: vittorio.giusti@chuv.ch 
